\title{
COMPORTAMENTO DE BUSCA NA INTERNET: Um estudo exploratório em salas comunitárias
}

\author{
INFORMATION SEEKING BEHAVIOUR ON THE INTERNET: \\ an exploratory study in community access centres
}

\author{
Ariadne Chlöe Mary Furnival - chloe@power.ufscar.br \\ Professora Adjunta do Departamento de Ciência da Informação \\ Universidade Federal de São Carlos (UFSCar) \\ Veridiana Abe-veridiana80@yahoo.com.br \\ Mestranda no Programa de Pós-Graduação em Ciência da Informação \\ Universidade Federal de Santa Catarina (UFSC)
}

\begin{abstract}
Resumo
Estudo sobre o comportamento de busca de informação dos usuários das salas de Internet existentes em duas instituições numa cidade do interior do estado de São Paulo, que promovem o acesso gratuito à comunidade, assim contribuindo ativamente ao processo de inclusão digital. A análise do comportamento de busca de informação dos usuários visou identificar a estratégia global de busca empregada, compreendendo a utilização da sintaxe e semântica de busca, as fontes de informação e os usos da Internet. Foram aplicados 61 questionários com perguntas fechadas e abertas e os resultados permitem afirmar que os usuários possuem pouca familiaridade com a Internet, efetuam em média 1 a 2 buscas e empregam poucos termos na formulação da expressão de busca, ainda que recuperem as informações que necessitam.
\end{abstract}

Palavras-chave: Comportamento de busca de informação. Inclusão digital. Internet. Estratégias de busca de informação. Alfabetismo em informação

\section{INTRODUÇÃO: INCLUSÃO DIGITAL E INFORMATION LITERACY}

As profundas alterações decorrentes da globalização da economia, do aprofundamento do capitalismo e da introdução das tecnologias da informação e da comunicação (TICs), afetaram o mundo e alteraram as relações sociais, políticas e econômicas mundiais. A dimensão espaço-tempo foi irreversivelmente afetada pelo uso maciço das TICs, unindo organizações, estados e pessoas em uma rede global, conectada em tempo real, em que o uso da Internet para a recuperação da informação torna-se essencial para a inclusão social de parcela da população que necessita adquirir informação. Nesse contexto, o Brasil aparece em $65^{\circ}$ colocado entre os países com maior acesso digital, segundo relatório do ranking mundial de acesso às TICs, divulgado pela União Internacional de Telecomunicações (UIT) da Organização das Nações Unidas (ONU) (PIRES, 2003).

Tadao Takahashi (2000, p. 31), coordenador do Grupo de Implantação do Programa Sociedade da Informação (Socinfo) no Brasil, lançado pelo Ministério da Ciência e 
Tecnologia (MCT) em 2000, frisa que o acesso às TICs não constitui um fim em si mesmo, mas que é imprescindível também promover a "alfabetização tecnológica" para que os cidadãos possam se tornar usuários efetivos dos recursos informacionais oferecidos. Ele nota que:

[A] universalização de serviços da Internet tem sido complementada por ações focadas em pelo menos três frentes: educação pública, informação para a cidadania e incentivo à montagem de centros de serviço de acesso público à Internet. (TAKAHASHI, 2000, p.33).

Silveira (2001, p. 81), ao referir-se ao Programa, frisa que "há o reconhecimento de que no Brasil e em todo o mundo, parte das desigualdades entre pessoas e instituições é resultado da assimetria no acesso e entendimento da informação disponível". Essa assimetria decorre das distorções relativas inicialmente - mas não único fator - ao acesso às TICs, em que a Internet torna-se cada vez mais uma poderosa ferramenta de inclusão e exclusão digital e social, esta última compreendida aqui de maneira geral, porém não tão simplista quanto a imagem contida no binômio inclusão/exclusão possa sugerir. Para a Organização para a Cooperação e Desenvolvimento Econômico (OCDE), citado por Iizuka, a exclusão digital refere-se à:

[...] distância entre indivíduos, famílias, empresas e regiões geográficas em diferentes níveis sócio-econômicos com respeito, simultaneamente, às suas oportunidades de acesso às tecnologias de informação e comunicação (TICs) e o uso da Internet para uma ampla variedade de ações e atividades. (IIZUKA, 2002, p. 4).

Não se pode subestimar as necessidades criadas e expectativas geradas em torno da inclusão digital, questão extremamente problemática quando se estende a perspectiva do binômio simplista exclusão/inclusão social ao âmbito do digital. Ou seja, perceber a inclusão digital como fator de inclusão social cria uma falácia: a crença de que incluir digitalmente as pessoas proporcionará melhores oportunidades de emprego e renda. Sobre essa questão, Amartya Sem, citado por Iizuka, nota:

[...] cria-se uma expectativa de que ao fazer um curso de informática ou atualizar-se em ferramentas tecnológicas, haverá uma oportunidade de emprego em troca. Essa é uma promessa no mínimo perigosa e até mesmo irresponsável, pois quem pode garantir que uma capacitação em tecnologia seja um passaporte para o mundo do trabalho? (IIZUKA, 2002, p. 5).

Uma outra questão relativa à inclusão digital, refere-se ao alfabetismo em informação (information literacy). Se a questão do acesso às TICs constitui uma etapa necessária para que haja inclusão digital, necessário também seria focar ações que pudessem desenvolver habilidades informacionais em ambientes eletrônicos, para que os usuários pudessem ser capazes de avaliar e usar a informação em favor de seus interesses. Logo, uma pessoa alfabetizada em informação seria capaz de "identificar a necessidade de informação, organizá-la e aplicá-la na prática, integrando-a a um corpo de conhecimentos existentes e usando-a na solução de problemas." (SILVA, 2005, p. 33).

Há, ainda, os termos "alfabetização tecnológica" ou "alfabetização digital", havendo autores como Buzato, citado por Silva (SILVA, 2005, p. 33), que defende o emprego de 
"letramento digital", uma vez que há pessoas que são alfabetizadas, mas "não são necessariamente "letradas", pois, mesmo sabendo ler e escrever, não conseguem redigir um convite formal, interpretar um gráfico, encontrar um livro em um catálogo etc". Afirma que essa competência se constrói na prática social, e não na aprendizagem em si. Logo, letramento digital, para Buzato, seria a expressão mais adequada, porque seria "a habilidade para construir sentido, capacidade para localizar, filtrar e avaliar criticamente informação eletrônica, estando essa em palavras, elementos pictóricos, sonoros ou qualquer outro". (BUZATO apud SILVA, 2005, p. 33). Nesse sentido, um dos desafios da inclusão digital seria, em um primeiro momento, pensar a questão do acesso às TICs e, talvez simultaneamente, dirimir esforços para a elaboração de programas educacionais capazes de promover competências informacionais information literacy - a fim de que os usuários (ou estudantes) possam ser capazes de identificar fontes de informação, selecioná-las e avaliar criticamente a informação recuperada.

Inicialmente, dadas as condições econômicas e sociais da população brasileira e do grau de desenvolvimento tecnológico do país, ainda que as iniciativas atuais que visem combater a exclusão digital por meio da disponibilização de acesso comunitário à Internet, não ponham fim às disparidades sociais e econômicas, tais iniciativas podem contribuir para diminuir o fosso entre aqueles que possuem acesso e aqueles que não possuem, ao possibilitar sua aproximação às TICs e, conseqüentemente, às informações disponibilizadas na Internet.

A quantidade de informação disponível na Internet é imensa e tende a crescer exponencialmente, o que configura um desafio para aqueles que precisam satisfazer a sua necessidade de informação e por outro lado, desafia profissionais envolvidos no desenvolvimento de sistemas relacionados à recuperação da informação e educadores preocupados com o uso da Internet, enquanto poderosa ferramenta de informação. Isso porque, apesar dos avanços na pesquisa com as interfaces de processamento de linguagem natural, os usuários ainda estão obrigados a dialogar com as bases de dados e com a informação, seja na Internet, em CD-ROMs ou em Catálogos Online de Acesso Público, nos próprios termos daquelas bases. Isto é, o usuário ainda se encontra na situação em que tem que adequar a sua estratégia de busca nos próprios termos daquelas bases, e não vice-versa. Na maior parte das vezes, isto implica que o usuário está obrigado a se familiarizar minimamente com as noções básicas da lógica booleana, usualmente disponibilizadas no menu Help ou em "busca avançada", se quiserem alcançar uma precisão e exaustividade razoáveis. Logo, compreender como os usuários recuperam a informação e quais as percepções possuem sobre a Internet é um dos objetivos desse trabalho exploratório.

Por essa razão, enfocamos neste trabalho um aspecto da chamada "alfabetização digital" ou, mais adequadamente, do "letramento digital": o uso da Internet para a recuperação da informação. Inseridos nesse contexto, situam-se na mesma cidade do interior de São Paulo, duas instituições que buscam promover a inclusão digital - e, por extensão, social - da comunidade, através da disponibilização gratuita de acesso à Internet: o Serviço Social do Comércio, (SESC) e o Centro de Divulgação Científica e Cultural (CDCC), ligado à USP. 
O foco deste trabalho não reside em delinear que tipo de informação os usuários buscam na Internet, mas sim como buscam e como avaliam a informação recuperada na Internet. Assim algumas perguntas foram essenciais em um primeiro momento: "Como os usuários desses centros de acesso recuperam a informação que necessitam naquele momento?" e "Qual a estratégia de busca empregada por esses usuários?" A esse respeito, utiliza-se a expressão estratégia de busca para se referir à forma mais global da tomada de decisão no processo de busca de informação, em comparação com o termo expressão de busca, que pode ser formulada após a escolha de uma estratégia. Esta última é o caso das expressões redigidas com ou sem o uso de operadores booleanos ou outros conectivos, sintáticos inclusive.

Para compreender qual estratégia é adotada pelo usuário, adotou-se a perspectiva dos estudos sobre comportamento de busca de informação dos usuários - campo de estudos muito fecundo na área de Ciência da Informação - focalizando um contexto específico de recuperação da informação, buscando avaliar como os usuários compreendem e fazem uso dos recursos oferecidos pela Internet, nos diferentes locais de acesso à Internet gratuitos pesquisados que, por sua vez, possuem limitações de tempo e constituem um espaço físico compartilhado por diferentes pessoas e interesses diversos.

\section{COMPORTAMENTO DE BUSCA DA INFORMAÇÃO}

O campo de pesquisas sobre comportamento informacional (tradução para information behavior) emergiu a partir de estudos realizados por cientistas, antes mesmo do termo Ciência da Informação ter sido cunhado. Wilson (1999, p. 250) apresenta como origem desse campo de pesquisa a Conferência de Informação Científica da Royal Society, realizada em 1948, ocasião em que muitos estudos sobre comportamento de busca da informação foram apresentados - embora sem o emprego do termo comportamento informacional - com reflexões orientadas às necessidades de informação de usuários, principalmente usuários especializados, como cientistas e pesquisadores (FERREIRA, 1997) e sobre documentação e uso de bibliotecas (WILSON, 1999). A partir de então, estudos enfocando como pesquisadores e estudiosos procedem para obter informações foram numerosos e delinearam diferentes fases, segundo Ferreira (1997):

Década de 40: os estudos restringiam-se à área de Exatas e objetivavam agilizar e aperfeiçoar os produtos e serviços oferecidos pelas bibliotecas;

Década de 50: intensificaram-se os estudos sobre o uso da informação entre grupos específicos de usuários, englobando as Ciências Aplicadas;

Década de 60: nessa época, os estudos passam a contemplar questões relativas ao comportamento de usuários, como tecnólogos e educadores, surgindo estudos de fluxos da informação, canais formais e informais. Data desse período o crescimento de estudos que analisam os diferentes aspectos de busca e uso da informação, designando os estudos sobre "Necessidades e Usos da Informação";

Década de 70: neste período, emergem estudos relativos aos usuários e à satisfação de suas necessidades de informação, caracterizando-se como estudos de necessidades que, 
por sua vez, passariam a divergir em duas direções: abordagem tradicional (systemoriented approach ou traditional approach), dirigida sob a ótica do sistema de informação; e abordagem alternativa, dirigida sob a ótica do usuário (user-oriented approach ou alternative approach. São dessa época estudos sobre usuários das áreas de humanas, ciências sociais e administrativas;

A partir da década de 80 , os estudos passaram a enfocar a avaliação de satisfação e desempenho.

Para Wilson (1999, p. 250), uma das principais críticas feitas a esses estudos dirigia-se ao fato dessas pesquisas não terem sido construídas com base em pesquisas prévias, de maneira a formarem um corpo teórico e de estudos empíricos que poderiam servir como ponto de partida para pesquisas futuras. Algumas razões para a emergência dessas críticas seriam a tradição positivista, cuja influência é perceptível nos estudos realizados inicialmente, que adotaram métodos quantitativos - inadequados, segundo Wilson para estudos do comportamento humano, o que teria gerado pesquisas orientadas para a quantificação (número de itens citados, de visitas à bibliotecas, dentre outros), razão pela qual pouquíssimos estudos dessa natureza conseguiram criar insights para o desenvolvimento de teorias ou práticas. Em segundo lugar, o fato de pesquisadores da CI ignorarem trabalhos desenvolvidos em outras áreas do conhecimento, que poderiam oferecer modelos teóricos mais adequados ao estudo do comportamento humano e, em terceiro lugar, o fato de estudos voltados a essas questões terem emergido há apenas quinze anos, aproximadamente, época em que a CI passou a enfocar a efetividade da comunicação do conhecimento e sua representação entre os seres humanos; o uso e a necessidade da informação e as tecnologias da informação (LIMA, 2003, p. 78).

Contudo, nas últimas décadas, esse quadro vem sendo modificado, em decorrência da aplicação de métodos qualitativos, abundantes principalmente em estudos britânicos, que possuem grande tradição em estudos de comportamento. Alguns trabalhos de pesquisadores têm influenciado a elaboração de mais estudos na área, como é o caso das abordagens das norte-americanas Kulthau e Dervin, e dos trabalhos de Wilson, Ellis e, mais recentemente, Foster, docentes de universidades inglesas, cujas influências podem ser percebidas nos inúmeros estudos aplicados a comunidades de usuários específicos principalmente acadêmicos - existentes na literatura internacional. Sucintamente, esses estudos têm identificado a busca de informação em muitos níveis, como: estudos nos quais são descritas atividades e tarefas específicas; estudos de necessidades e usos de fontes de informação por grupos específicos; estudos que têm identificado aspectos afetivos ou cognitivos de usuários e modelos teóricos e descritivos de busca de informação, busca de informação em sistemas de informação ou comportamento informacional.

Uma das dificuldades percebidas durante a busca de bibliografia adequada para tratar este tema, refere-se à multiplicidade de terminologias e conceitos empregados por pesquisadores da mesma área e de áreas distintas. Os diferentes significados e usos das terminologias e conceitos se devem à interdisciplinaridade da área e, em segundo lugar, $\mathrm{o}$ fato de que os termos information behaviour, information searching behavior $\mathrm{e}$ information seeking behavior possuem significados muito semelhantes em português. Além disso, a expressão comportamento informacional - information behaviour - 
surgiu como uma alternativa, segundo Wilson (1999, p.252) à expressão "necessidades de informação", bastante utilizada e disseminada na literatura nacional e estrangeira.

De maneira geral, pode-se compreender comportamento informacional como a totalidade de fontes e canais de informação, incluindo uso e busca de informação. Está implícita também, a comunicação com outras pessoas e a recepção passiva da informação. Para Krikelas (1983, p. 6-7) comportamento de busca de informação pode ser definido como:

[...] qualquer atividade de um indivíduo que compromete-se a identificar uma mensagem que satisfaça a uma necessidade percebida. Em outra palavras, a busca de informação tem início quando alguém percebe que o seu atual estado de conhecimento é menor do que o necessário para lidar com algum assunto [ou problema]. (Tradução nossa).

$\mathrm{Na}$ tentativa de esclarecer os recortes dessa área, empregaremos a distinção constante no trabalho de Wilson (1999), que propõe um modelo conceitual para as áreas de pesquisa sobre comportamento informacional, com base nos estudos já realizados por outros pesquisadores. Abaixo, as definições segundo Wilson:

- information behaviour (comportamento informacional): campo mais geral de investigação e relacionado ao comportamento da informação. Inclui a totalidade de fontes e canais de comunicação, incluindo busca de informação passiva (assistir a TV, por exemplo) e ativa (comunicação face a face), sem a intenção de agir sobre a informação que lhes é dada;

- information seeking-behaviour (comportamento de busca de informação): sub-campo do campo, relativo à variedade de métodos que as pessoas empregam para ter acesso às fontes de informação para atender a uma necessidade e satisfazê-la;

- information searching behaviour (comportamento de busca em sistemas de informação): campo menor, relativo às interações entre usuário da informação (com ou sem um intermediário) e sistemas de informação computadorizados.

A Figura 1 apresenta as relações entre essas áreas:

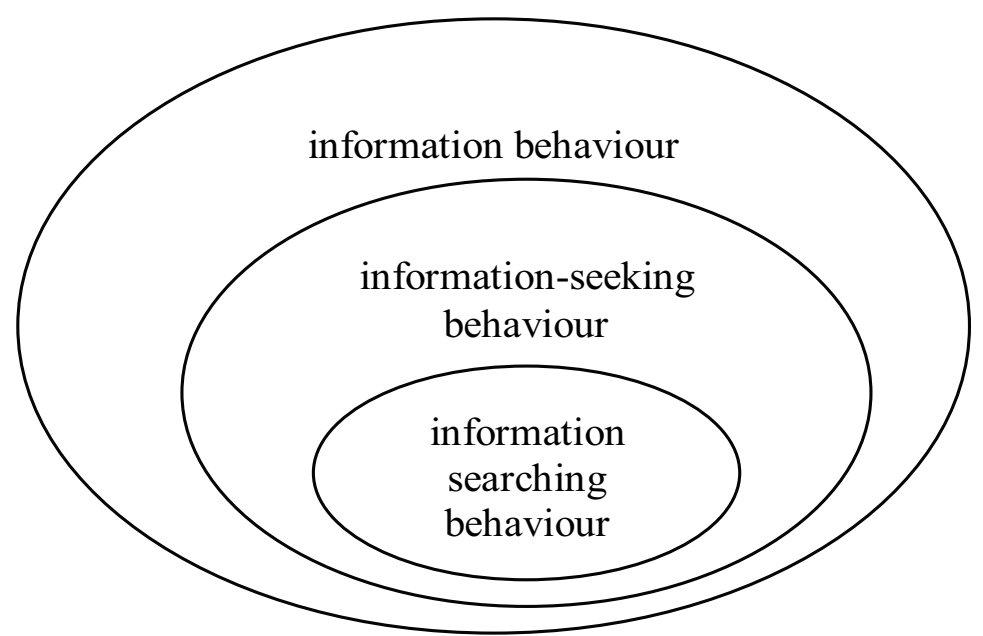

FIGURA 1 - Modelo das áreas de pesquisa em busca de informação e busca de informação em sistemas de informação computadorizados

Fonte: Wilson (1999, p. 263) 
A construção desse tipo de modelo facilita a compreensão sobre o objeto de pesquisa, advindo daí a importância da construção de modelos conceituais que, ainda que não constituam teorias, são instrumentos válidos e capazes de orientar futuras pesquisas, a fim de auxiliar na elaboração de design de sistemas de informação e de programas de educação para o desenvolvimento de competências informacionias e outras pesquisas.

Ressaltamos que na literatura encontrada sobre comportamento de busca de informação, a distinção proposta por Wilson - information searching behaviour e information seeking behaviour - é de difícil percepção e em muitos casos, parece haver uma intersecção entre essas áreas, dada a variedade de estudos que focalizam tanto a interação entre usuário e sistema quanto a necessidade de satisfazer um objetivo de pesquisa. Contudo, o diagrama de Wilson auxilia na percepção do relacionamento (ou não) entre essas áreas e, entre outros aspectos, o diagrama torna-se importante para que a recuperação da informação sobre esse assunto seja mais clara, rápida e precisa.

$\mathrm{Na}$ literatura pesquisada sobre comportamento de busca de informação pôde-se encontrar estudos sobre information seeking behaviour: modelos conceituais e a aplicação em estudos empíricos ou comparação entre modelos (WILSON, 1999; ELLIS, 1989; FOSTER, 2003, 2004; KUHLTHAU, 1990; JÄRVELIN; WILSON, 2003; FERREIRA, 1997; CRESPO; CAREGNATO, 2003); influência de modelos mentais, objetivos de pesquisa e personalidade no comportamento de busca de informação (HEINSTRON, 2005; SLONE, 2002); aspectos cognitivos (BRANDT; UDEN, 2003; BRUCE, 1999); ocorrência de fenômenos interferentes durante a busca (serendipty) (FOSTER; FORD, 2003); estudos realizados com estudantes de escolas (HIRSH, 1999); estudos sobre information searching behaviour: estratégias de busca de informação e fatores influenciadores (WHITE; IIVONEN, 2001; KARI, 2004); desempenho de sistemas (SAVOY; PICARD, 2001; ALLEN, 2001); que descrevem as formulações de expressões de busca (semântica e sintaxe), ocorrência de falhas e erros decorrentes dessas formulações (JANSEN; SPINK; SARACEVIC, 2000); influências da atividade ou profissão do usuário em seu comportamento de busca; diferenças entre usuários experientes e novatos; modelos mentais (BRUCE, 1999; SLONE, 2002).

Um aspecto percebido nessa literatura refere-se ao fato desses estudos examinarem o comportamento de busca de usuários especializados, como estudantes de graduação, de pós-graduação e pesquisadores de diferentes áreas do conhecimento e, em menor escala, porém em ascensão, pesquisadores de áreas interdisciplinares. Estudos aplicados a usuários não especializados na Internet, ou seja, o cidadão comum, não vinculado a universidades ou centros de pesquisa não foram objeto desses estudos, excetuando o trabalho de Jansen, Spink e Saracevic (2000), que analisaram logs de máquinas de busca e averiguaram as estratégias empregadas pelos usuários de Internet sem, contudo, revelar quem são esses usuários e porque empregam determinadas estratégias, segundo seus próprios autores, e trabalhos envolvendo estudantes de escolas norte-americanas, correspondentes ao ensino fundamental e médio brasileiro (HIRSH, 1999).

Jansen, Spink e Saracevic (2000), haviam encontrado cenário semelhante na literatura, afirmando que a Web vem sendo foco de muitos estudos, sob diversos prismas, sendo que os principais dirigiram-se sob a ótica do: hardware, com a análise de uso de 
servidores; software, com a avaliação de ferramentas de buscas na Web; estatísticas de uso da Web, tão regularmente realizadas quanto rapidamente obsoletas; serviços de ferramentas de buscas e padrões de navegação de usuários na Web. Para eles, os estudos sobre busca de informação na Web não têm sido em grande escala (quantitativos ou qualitativos), se comparados ao grande volume de estudos realizados sobre usuários de catálogos online de acesso público.

No Brasil, a situação pouco difere, à exceção de que os estudos nessa área são mais escassos, sendo mais freqüentes estudos que abordam a necessidade de informação de usuários de redes eletrônicas de universidades e centros de informação especializados. Parece haver uma lacuna deixada por esses estudos, ao não contemplarem o comportamento de busca de informação na Internet de usuários comuns; cidadãos comuns que buscam informação - as mais variadas - para atender as suas necessidades. Logo, estudos com essa perspectiva poderiam ser elaborados, principalmente no atual estágio de desenvolvimento brasileiro que, por meio dos Programas de Inclusão Digital, propõe incluir digitalmente toda a população, com vistas a fortalecer o movimento de educação para a informação (information literacy education) - dada sua erupção atual - e subsidiar a formulação de propostas para a inclusão curricular de disciplinas para promover o desenvolvimento de habilidades informacionais.

A presente pesquisa, desenvolvida com os usuários das salas de Internet do SESC e CDCC, insere-se na no campo menor - information searching behaviour - porque investiga as diferentes estratégias de busca empregadas pelos usuários na interação com a Internet, não focalizando os objetivos de pesquisa dos usuários.

\section{OBJETIVOS E OPERACIONALIZAÇÃO METODOLÓGICA DO ESTUDO}

A pesquisa intentou compreender o comportamento de busca dos usuários das salas de Internet comunitárias disponíveis no SESC e CDCC-USP, visando também delinear, ainda que minimamente, o perfil desses usuários, a fim de, espera-se, subsidiar políticas públicas locais que visam incentivar iniciativas de inclusão digital na cidade. Posto isso, os objetivos específicos do estudo foram os de:

- identificar qual estratégia de busca global é empregada por estes usuários;

- examinar como tais usuários formulam suas expressões de busca de informação em vista da semântica e sintaxe das expressões;

- identificar quais fontes de informação os usuários consultam para interagirem com o sistema;

- identificar quantas vezes e como os usuários modificam (ou não) suas expressões de busca;

- determinar quais modelos teóricos podem ser aplicados para a compreensão dos comportamentos de busca desses grupos de usuários.

À época da elaboração do projeto de pesquisa, no ano de 2006, pretendia-se aplicar um questionário sucinto, com perguntas fechadas e semi-abertas, nos locais nos quais a busca por informação estivesse sendo realizada. Assim, intentava-se realizar uma pesquisa quantitativa (CHIZZOTTI, 1991). Com base numa revisão da literatura sobre métodos e técnicas, passou-se à elaboração de um primeiro questionário misto, 
contendo 17 perguntas fechadas e abertas. Esta primeira versão foi testada, e várias modificações foram subseqüentemente feitas. Uma das dificuldades observadas nesse período residiu na questão relativa aos termos que deveriam ser empregados para dialogar com o usuário. Notou-se que expressões como: ferramenta de busca, termos, conectivos lógicos, sinais gráficos, Web, sites, portais temáticos entre outros, pareceriam confusos ao usuário, dada a ausência de precisão no uso desses termos. Por essa razão, a linguagem apresentada na versão final do questionário buscou aproximarse do universo desses usuários, utilizando expressões mais gerais.

A fase da pré-teste também nos chamou a atenção para o fato de que o tamanho do instrumento e o modo de aplicá-lo seriam os aspectos-chave para o sucesso da pesquisa. Logo, era imperativo que o questionário fosse o mais curto possível.

Foram aplicados 61 questionários, sendo 37 no CDCC e 24 no SESC, durante o período de outubro a dezembro (2005). Devido ao fato dessa pesquisa abranger duas instituições distintas, ocorreram diferenças na sistemática de aplicação em um local e outro. No CDCC, os usuários foram mais receptivos e dispostos a responder ao questionário, não havendo muitas recusas e, logo, foi possível a aplicação no momento mesmo do acesso à Internet. Isso talvez se devesse ao fato do tempo de permanência nas máquinas ser de uma hora e à própria dinâmica do local: a sala do CDCC é bastante iluminada naturalmente e observou-se que muitos usuários sentavam-se em duplas ou trios, criando uma atmosfera mais "informal". Diversamente, no SESC, o tempo de permanência é de meia hora, período considerado curto pelos usuários. Assim, obtivemos muitas recusas - em uma sessão (ou horário), foram 13 abordagens e 13 recusas; na sessão seguinte, dos 12 usuários usando computadores, apenas 1 concordou em responder ao questionário após o encerramento da sessão, mas ao término de seu horário, o usuário esquivou-se. Essas recusas por parte dos usuários em responder ao questionário no momento do acesso, fez com que a abordagem fosse realizada momentos anteriores ou posteriores ao acesso, enquanto os usuários estivessem na sala de leitura aguardando o seu horário, ou com usuários que já haviam utilizado os computadores e encontravam-se esperando seus amigos.

Durante a aplicação do instrumento de coleta, paulatinamente os usuários complementavam as suas respostas (conforme averiguado na aplicação do pré-teste), explicando seus interesses e tecendo comentários acerca das qualidades e deficiências da Internet. Este foi um aspecto essencial, porque o questionário, ainda que contivesse perguntas abertas e em outras questões possibilitasse que o usuário enumerasse a ordem de preferência das respostas ou ainda, marcasse várias alternativas, seus comentários dificilmente poderiam se enquadrar em alguma resposta. Os comentários tecidos pelos usuários foram importantes, porque forneceram elementos adicionais para a consecução da análise dos dados. Dessa forma, essa complementação qualitativa respondeu a questões muito particulares e permitiu trabalhar com um nível de realidade que não pode ser quantificado. Isso não exclui que os dados quantitativos coletados não possam receber um tratamento qualitativo. 


\section{RESULTADOS E DISCUSSÃO}

Foram aplicados 61 questionários, dos quais 37 no CDCC e 24 no SESC. A comunidade de usuários pesquisada foi constituída predominantemente por estudantes de 11 a 18 anos. O SESC promove cursos de Internet para a $3^{\mathrm{a}}$ idade com o intuito de incluir digitalmente esse segmento, e por isso, houve maior presença de usuários com mais de 50 anos no SESC. No entanto, a presença de adultos no SESC e CDCC, entre 27 e 50 anos, mostrou-se pequena e a coleta de informações junto a eles apontou que usavam a Internet principalmente para procurar informações sobre emprego, para preenchimento de formulários governamentais, elaboração de currículos e pesquisas pessoais. A presença de mulheres foi maior no CDCC (70\%), diferentemente do que ocorre no SESC, em que a presença de garotos foi predominante $(75 \%)$, possivelmente devido ao fato de que no SESC, é permitido aos usuários baixarem jogos da Internet, sendo muito freqüente encontrar os garotos reunidos em grupos e jogando entre eles, fato que não ocorria no CDCC, onde essa prática não é permitida.

\subsection{Perfil dos usuários}

O grau de escolaridade dos estudantes predominantemente foi o ensino médio, seguido pelo ensino fundamental, não sendo encontradas diferenças significativas entre as duas instituições, conforme mostrado na Tabela 1. A ocupação dos usuários indicou que $67,2 \%$ dos usuários apenas estudavam e 19,7\% dos usuários pesquisados trabalhavam (Tabela 2).

Tabela 1 - Grau de escolaridade dos usuários

\begin{tabular}{c|ccc}
\hline & Fundamental & Médio & Superior \\
\hline CDCC & $12(32,4 \%)$ & $24(64,9 \%)$ & $1(2,7 \%)$ \\
SESC & $9(37,5 \%)$ & $12(50 \%)$ & $3(12,5 \%)$ \\
Total & $21(34 \%)$ & $36(59 \%)$ & $4(6,6 \%)$ \\
\hline
\end{tabular}

Tabela 2 - Ocupação dos usuários

\begin{tabular}{l|llll}
\hline & $\begin{array}{l}\text { Estudam e não } \\
\text { trabalham }\end{array}$ & Estudam e trabalham & $\begin{array}{l}\text { Trabalham e não } \\
\text { estudam }\end{array}$ & Não trabalham e não estudam \\
\hline CDCC & $27(73 \%)$ & $3(8,1 \%)$ & $5(13,5 \%)$ & $2(5,4 \%)$ \\
SESC & $14(58,3 \%)$ & - & $4(16,7 \%)$ & $6(25 \%)$ \\
Total & $41(67,2 \%)$ & $3(4,9 \%)$ & $9(14,7 \%)$ & $8(13,1 \%)$ \\
\hline
\end{tabular}

Entre os usuários que trabalham, observou-se que no SESC, predominou a incidência de profissionais liberais, fato que pode ser compreendido em razão do horário da aplicação dos questionários ter sido realizado durante o período de trabalho. No CDCC, a profissão dos usuários mostrou-se diversificada.

No CDCC, $86,4 \%$ dos usuários não possuem computador em casa e $13,5 \%$ possuem computador. No SESC, a situação foi mais equilibrada: metade dos usuários tem 
computador em casa. Em ambos os locais, dentre os 17 usuários que possuem computador em casa, 4 usuários não têm acesso à Internet. Entre os usuários que possuem Internet em casa, foi solicitado, informalmente que dissessem se utilizavam-na diariamente. Sete usuários do CDCC, alegaram que em suas casas, seus pais permitem que acessem a Internet apenas aos finais de semana, "para não prejudicar os estudos e porque é muito caro". Verificou-se que os usuários despendem de 1 a 2 horas na Internet e tiveram o primeiro acesso à Internet entre 2 e 4 anos anteriores à pesquisa (Tabela 3). Contudo, o acesso à Internet não foi constante, porque a eles não havia a possibilidade de acesso, segundo o depoimento de 20 dos respondentes. Nesse sentido, essas afirmações vão ao encontro da questão dos altos custos de acesso para usuários domésticos, segundo as estimativas constantes no Programa Sociedade da Informação, ainda que possuam um computador, este não é suficiente para garantir o acesso efetivo à Internet.

Tabela 3 - Tempo de uso da Internet e horas despendidas

\begin{tabular}{c|ccccccccccc}
\hline & \multicolumn{4}{|c}{ Horas de uso na Internet (por semana) } & \multicolumn{5}{c}{ Primeiro contato com a Internet (em anos) } \\
\hline & até 1 & 1 a 2 & 3 a 5 & 5 a 7 & 7 a 15 & +20 & até 1 & 1 a 2 & 2 a 3 & 3 a 4 & +4 \\
Total & 2 & 29 & 12 & 9 & 7 & 2 & 3 & 8 & 18 & 18 & 12 \\
$\%$ & $3,3 \%$ & $47,5 \%$ & $19,7 \%$ & $14,8 \%$ & $11,5 \%$ & $3,3 \%$ & $5,1 \%$ & $13,6 \%$ & $30,5 \%$ & $30,5 \%$ & $20,3 \%$ \\
\hline
\end{tabular}

Os usuários acessam a Internet de diferentes locais, como da Biblioteca Pública (Tabela 4), citada apenas entre os usuários do $\mathrm{CDCC}$, talvez por esta localizar-se na região central da cidade, próxima ao CDCC. Dentre os usuários que utilizam locais de acesso à Internet pagos, como cybercafés, os 7 usuários do SESC que afirmaram freqüentar tais locais o faziam devido à possibilidade de baixar jogos da Internet.

Tabela 4 - Locais de acesso à Internet

\begin{tabular}{l|ccccccccc}
\hline & \multicolumn{10}{c}{ Locais de acesso } \\
\hline $\begin{array}{l}\text { N. }{ }^{\text {o de }} \\
\text { usuários }\end{array}$ & Casa & $\begin{array}{c}\text { Casa de } \\
\text { amigos }\end{array}$ & $\begin{array}{c}\text { Local de } \\
\text { trabalho }\end{array}$ & Escola & SESC & CDCC & $\begin{array}{c}\text { Locais } \\
\text { pagos }\end{array}$ & $\begin{array}{c}\text { Biblioteca } \\
\text { pública }\end{array}$ & Outros \\
& 13 & 13 & 2 & 5 & 27 & 41 & 13 & 6 & 2 \\
\hline
\end{tabular}

Os usuários aprenderam a navegar na Internet de três formas: ajuda especializada, compreendendo curso de Internet, assistência de monitores ou mesmo pela leitura de revistas especializadas no assunto; ajuda informal, relativa ao aprendizado em que o usuário aprende a navegar na rede sozinho ou recebe dicas e auxílio de amigos e familiares; ou aprenderam de ambas as formas (Tabela 5). Vale ressaltar que se averiguou um alto índice de usuários que fizeram um curso de Internet pago $(45,9 \%)$. 
Tabela 5 - Modo de aprendizado na Internet

\begin{tabular}{l|cccccc}
\hline & \multicolumn{5}{c}{ Em porcentagem } \\
\hline CATEGORIAS & CDCC & SESC & Total & CDCC & SESC & Total \\
Informal & 13 & 10 & 23 & $35 \%$ & $42 \%$ & $38 \%$ \\
Ajuda & 9 & 8 & 17 & $24 \%$ & $33 \%$ & $28 \%$ \\
especializada & 15 & 6 & 21 & $41 \%$ & $25 \%$ & $34 \%$ \\
Ambas & & & & & & $34 \%$ \\
\hline
\end{tabular}

Os usuários utilizam a Internet predominantemente para pesquisas escolares e interesse pessoal (Tabela 6). Foram analisadas as respostas a duas perguntas constantes no questionário: uma aberta e outra fechada. As respostas enquadradas na categoria interesse pessoal foram variadas: jogos, informação, curiosidades, passatempo, diversão, lazer, pesquisas (carros, fã-clube, bandas, seriado da rede Globo Malhação) e receitas culinárias. Na categoria trabalho foram agrupadas as respostas relativas à busca por emprego, atualização profissional, preenchimento de formulários. $\mathrm{Na}$ categoria comunicação foram citados predominantemente bate-papo e MSN; minoritariamente (apenas 2 usuários) o uso de e-mails.

Tabela 6 - Motivações para o uso da Internet

\begin{tabular}{|c|c|c|c|c|c|c|c|c|}
\hline & \multicolumn{8}{|c|}{ Uso da Internet } \\
\hline & \multicolumn{2}{|c|}{ Interesse pessoal } & \multicolumn{2}{|c|}{ Trabalho } & \multicolumn{2}{|c|}{ Pesquisas escolares } & \multicolumn{2}{|c|}{ Comunicação } \\
\hline & $\mathrm{CDCC}$ & SESC & CDCC & SESC & $\mathrm{CDCC}$ & SESC & $\mathrm{CDCC}$ & SESC \\
\hline Estudam apenas & 16 & 12 & 1 & - & 17 & 10 & 3 & 7 \\
\hline $\begin{array}{l}\text { Trabalham e não } \\
\text { estudam }\end{array}$ & 7 & 4 & 3 & 2 & - & - & - & 2 \\
\hline $\begin{array}{l}\text { Trabalham e } \\
\text { estudam }\end{array}$ & - & - & 1 & - & 1 & - & - & - \\
\hline $\begin{array}{l}\text { Não trabalham e não } \\
\text { estudam }\end{array}$ & - & 7 & 1 & 1 & - & - & - & 3 \\
\hline $\mathrm{N}^{\mathrm{o}}$ de respostas & 23 & 23 & 6 & 3 & 18 & 10 & 3 & 12 \\
\hline $\mathrm{N}^{\mathrm{o}}$ total de respostas & & 46 & & 9 & & 28 & & 15 \\
\hline
\end{tabular}

\subsection{Comportamento de busca da informação dos participantes da pesquisa}

Foi solicitado aos usuários que enumerassem, em ordem de preferência, as fontes que utilizavam para obter informação. Analisando-se os dados, $83,6 \%$ dos usuários consultam três a quatro das fontes enumeradas e 3,2\% utilizam apenas a Internet como fonte de informação. Mesmo assim, percebe-se que a maioria dos participantes usa a Internet como uma fonte de informação, ainda que esta não seja a única. Quando os usuários necessitam de informação, suas escolhas sobre as fontes de informação utilizadas recaem sobre a seguinte ordem de prioridade, conforme a Tabela 7. 
Tabela 7 - Fontes de informação dos usuários

\begin{tabular}{|c|c|c|c|c|c|c|c|c|c|c|c|c|c|c|c|c|c|c|c|c|c|c|c|c|}
\hline & \multicolumn{5}{|c|}{$\begin{array}{l}\text { Amigos/ } \\
\text { Professores }\end{array}$} & \multicolumn{4}{|c|}{$\begin{array}{l}\text { Material que } \\
\text { possui em casa }\end{array}$} & \multicolumn{5}{|c|}{ Biblioteca } & \multicolumn{5}{|c|}{ Outro } & \multicolumn{5}{|c|}{ Internet } \\
\hline & $1^{o}$ & $2^{o}$ & $3^{\circ}$ & $4^{\circ}$ & $\begin{array}{l}\mathbf{T} \\
\mathbf{0} \\
\mathbf{t} \\
\mathbf{a} \\
\mathbf{l}\end{array}$ & $1^{\mathrm{o}}$ & 2 & $3^{\circ}$ & $\begin{array}{l}\mathbf{T} \\
\mathbf{o} \\
\mathbf{t} \\
\mathbf{a} \\
\mathbf{l}\end{array}$ & $1^{\mathrm{o}}$ & 2 & $3^{\circ}$ & $4^{\circ}$ & $\begin{array}{l}\mathbf{T} \\
\mathbf{o} \\
\mathbf{t} \\
\mathbf{a} \\
\mathbf{l}\end{array}$ & $1^{\mathrm{o}}$ & $2^{\circ}$ & $3^{\circ}$ & $5^{\circ}$ & $\begin{array}{l}\mathbf{T} \\
\mathbf{o} \\
\mathbf{t} \\
\mathbf{a} \\
\mathbf{l}\end{array}$ & $1^{\mathrm{o}}$ & 2 & $3^{\circ}$ & $4^{\circ}$ & $\begin{array}{l}\mathbf{T} \\
\mathbf{0} \\
\mathbf{t} \\
\mathbf{a} \\
\mathbf{l}\end{array}$ \\
\hline CDCC & 10 & 3 & 2 & 1 & 16 & 9 & 2 & 2 & 13 & 6 & 9 & 5 & 2 & 22 & 1 & 2 & 2 & & 5 & 15 & 12 & 2 & 3 & $\begin{array}{l}3 \\
2\end{array}$ \\
\hline SESC & 2 & 3 & 4 & 1 & 10 & 6 & 1 & & 7 & 1 & 7 & 2 & & 10 & 7 & 1 & 2 & 1 & 10 & 10 & 6 & 1 & 1 & $\begin{array}{l}1 \\
8\end{array}$ \\
\hline Total & & & & & 27 & & & & 20 & & & & & 32 & & & & & 15 & & & & & 50 \\
\hline
\end{tabular}

Os usuários iniciam as suas buscas na Internet majoritariamente por uma ferramenta de busca. $\mathrm{O}$ endereço certo (URL) foi respondido por usuários que tinham um objetivo específico e recorriam àquele endereço várias vezes (exemplo: quando os usuários acessavam a Internet para baixar jogos). Os resultados, conforme a Tabela 8, apontaram que a busca por mecanismos de busca predominou (Google, Cadê, Yahoo), seguida por sites, por assunto e pelo URL. Ressaltamos que essa pergunta foi aberta, por isso o alto índice de respostas sites. Ao perguntar aos usuários que sites eram esses, um usuário respondeu que "era só digitar o nome do que eu quero e aí aparece aí eu sigo". Esmiuçando as respostas, averiguou-se, junto a esse usuário, que site era indicativo de ferramentas de busca, como o Google. Nos demais questionários em que havia respostas iguais a essa, constatou-se que 8 entre 10 usuários haviam iniciado as suas buscas pelo Google e dois pelo Cadê. Na categoria "outros", as respostas não puderam ser agrupadas em nenhuma categoria, dada a dificuldade dos usuários em responder a essa pergunta (os três usuários que escolheram essa categoria não possuíam familiaridade com a Internet).

Tabela 8 - Início da busca na Internet

\begin{tabular}{c|cc}
\hline Respostas espontâneas dos usuários & Número de respostas & $\begin{array}{c}\text { Ferra } \\
\text { menta } \\
\text { de } \\
\text { busca }\end{array}$ \\
\hline Google & 32 \\
Cadê & 16 \\
Yahoo & 2 \\
Sites & 10 \\
\hline Endereço & 5 \\
Assunto & 1 \\
Outros & 3 \\
Total de respostas & 69 \\
\hline
\end{tabular}

Ao analisar as expressões de busca que os usuários empregam, averiguou-se que os usuários formulam suas expressões de busca com uma palavra apenas ou com palavras após a outra, sem o uso de conectivos, e recuperam a informação que necessitam com 
duas formulações de expressão de busca (Tabela 9). Sobre isso, os estudos de Jansen et al. (2000), já haviam concluído que os usuários fazem pouco uso de operadores booleanos e raramente desenvolvem buscas complexas. Hsieh-Yee, citado por Lucas e Topi (2002, p. 96), comparou o uso de termos de busca empregados por usuários experientes e novatos em bases de dados bibliográficas. Os resultados apontaram que houve uma pequena variação na quantidade de termos empregados por esses dois grupos de usuários, sugerindo que o conteúdo do termo é mais importante do que a quantidade de termos empregados em uma busca. Jansen e Spink (2005, p. 363) em seus estudos realizados com usuários do Excite e Alltheweb, chegaram a resultados semelhantes por meio de análise de log: os usuários empregaram respectivamente 2,3 e 2,9 palavras em uma formulação de expressão de busca e visualizaram 1,7 e 2,2 resultados de páginas por formulação de expressão de busca sendo um número muito limitado de resultados visualizados. Analisando outros estudos realizados com usuários de Internet, encontrou-se que cerca de $80 \%$ dos usuários visualizam de 10 a 20 documentos recuperados.

Tabela 9 - Número de expressões formuladas à máquina de busca $\mathrm{X}$ expressão de busca

\begin{tabular}{|c|c|c|c|c|c|c|c|c|c|}
\hline \multirow{4}{*}{$\begin{array}{l}\text { Número de } \\
\text { expressões } \\
\text { formuladas }\end{array}$} & \multicolumn{9}{|c|}{ Expressão de busca } \\
\hline & \multirow{2}{*}{\multicolumn{2}{|c|}{1 palavra }} & \multirow{2}{*}{\multicolumn{2}{|c|}{$\begin{array}{c}\text { Palavras após a } \\
\text { outra }\end{array}$}} & \multicolumn{4}{|c|}{ Emprego de conectivos } & \multirow[t]{3}{*}{ Total } \\
\hline & & & & & \multicolumn{2}{|c|}{ Corretos } & \multicolumn{2}{|c|}{ Incorretos } & \\
\hline & $\mathrm{CDCC}$ & SESC & $\mathrm{CDCC}$ & SESC & $\mathrm{CDCC}$ & SESC & $\mathrm{CDCC}$ & SESC & \\
\hline $1 \mathrm{vez}$ & 8 & 1 & 2 & 3 & & & & 1 & $15(25 \%)$ \\
\hline 2 vezes & 5 & 3 & 11 & 7 & 1 & & 1 & & $28(46,7 \%)$ \\
\hline 3 vezes & 3 & & 2 & 1 & & & & & $6(10 \%)$ \\
\hline 4 ou mais & 1 & 2 & 3 & 2 & & 2 & & 1 & $11(18,3 \%)$ \\
\hline Total & 17 & 5 & 18 & 14 & 1 & 2 & 1 & 2 & $60(100 \%)$ \\
\hline Total geral & & 22 & & 32 & & 3 & & 3 & $60(100 \%)$ \\
\hline & & $(37 \%)$ & & $(53,3 \%)$ & & $(5 \%)$ & & $(5 \%)$ & \\
\hline
\end{tabular}

Sobre o emprego de conectivos, um usuário, ao descrever os sinais, disse: "uso o traço [operador de restrição] porque ele melhora a busca, não vem tanta coisa". Perguntando a ele como aprendera a usar, ele disse que aprendera "por tentativa e erro". Apenas 3 usuários sabiam que os sinais eram denominados operadores e serviam para ampliar ou restringir a busca. Os conectivos citados pelos usuários foram as aspas, and $e+$. Sobre o emprego de outros conectivos, um desses usuários, possivelmente o que apresentava ter maior conhecimento do emprego dos sinais, disse que havia esquecido os outros, porque era difícil usá-los. Pode-se inferir que há uma dificuldade do usuário dialogar com a linguagem booleana de recuperação (ou seja, os termos do sistema), fenômeno apontado também por White e IIvonen (2001). A primeira formulação de busca do usuário - isto é, a expressão de busca formulada pelo usuário em sua primeira tentativa para localizar a informação que necessita - constitui uma etapa importante da pesquisa (WHITE; IIVONEN, 2001). Nesta pesquisa, 29 usuários empregam apenas uma palavra por vez, número que entendemos como alto.

Ainda que se tenha aferido que 6 entre 61 os usuários fazem uso de conectivos, isso não significa que os usuários que não os empregam desconheçam a existência deles. Segundo os dados colhidos, 26 afirmaram conhecê-los, mas não os utilizam. Esses 
usuários afirmaram ter conhecimento do emprego dos conectivos através dos professores, "tentativa e erro" e revistas; nenhum soube através do menu "Ajuda" constante nas ferramentas de busca. As razões apresentadas pelos usuários para o não emprego dos conectivos foram: complicado usá-los; pouca quantidade de informação recuperada e "não gosto". Entre os que realmente não conhecem e não os empregam, foram $54 \%$ dos usuários.

Os usuários disseram estar satisfeitos com a Internet, porque recuperam a informação que necessitam. Apenas um usuário do SESC afirmou que "a Internet não recupera informação e é extremamente difícil procurar aquilo que eu quero". Procurou-se verificar a quem os usuários atribuíam a responsabilidade (o sucesso ou insucesso da busca de informação) pela informação recuperada na Internet. Dos resultados (tabela 10), pôde-se observar que os usuários atribuem às ferramentas de busca e à Internet o mérito pela informação recuperada, colocando-se como agentes passivos no processo de busca de informação, isto é, como se a informação estivesse reunida em um só lugar, não sendo de sua responsabilidade a recuperação da informação disponível.

Tabela 10 - Responsabilidade pela recuperação da informação

\begin{tabular}{l|ccc}
\hline & \multicolumn{3}{|c}{ Responsabilidade pela recuperação da informação } \\
\cline { 2 - 4 } & Máquina de busca & Internet & $\begin{array}{c}\text { Forma com que a expressão é } \\
\text { formulada }\end{array}$ \\
Número de respostas & 34 & 27 & 12 \\
\hline
\end{tabular}

\section{CONSIDERAÇÕES FINAIS}

É uma obviedade dizer hoje que a web traz uma variedade imensa de informação em várias formas flexíveis e atraentes de apresentação, e por causa disso, torna-se o mais difundido e usado sistema de informação no mundo. Também se sabe que o crescimento do uso da web/internet tem feito com que os usuários sejam confrontados, diariamente, com quantidades imensas de informação, espalhada em diversos sites, e freqüentemente mal-organizada (HOLSHCER; STRUBE, 2000). Dado o fato de que ser um usuário da web é sinônimo hoje da noção de ser um cidadão minimamente informado e inserido no tecido social, os governos de certos países (como o Brasil) são obrigados a fomentar a inclusão digital, que abrange o apoio à oferta de acesso à Internet das salas comunitárias.

A crescente importância da web no dia-a-dia dos cidadãos, e a relativa facilidade e até prazer no seu uso, não se traduzem em uma correspondente eficácia e satisfação com os resultados da recuperação da informação, como salientam os resultados do presente estudo.

Nosso estudo permite afirmar que os usuários da Internet pesquisados que utilizam salas comunitárias de acesso possuem pouco conhecimento tanto do funcionamento da Internet, quanto de suas diferentes ferramentas e tipos de sites disponibilizados. Apontou, também, que esses usuários adquirem - principalmente por meio de cursos pagos - as habilidades mínimas para navegar na web, mas que tais habilidades restringem-se a um conjunto muito limitado de estratégias de busca, as quais evidentemente comprometem os resultados da mesma. Não obstante, os participantes 
deste estudo pareciam estar conformados com tais limitações, inclusive implicitamente, "culpando" o search-engine ou site pelo baixo retorno de informações consideradas relevantes. Ou seja, parece haver uma imagem tacitamente internalizada por esses usuários, deles mesmos como impotentes diante deste sistema "todo poderoso", que se traduziria, infelizmente, em pouco interesse em saber mais das possibilidades de aperfeiçoar as estratégias de busca. Contudo, dadas as condições dos usuários dos locais pesquisados - limitações no tempo de acesso - acreditamos que pesquisas futuras poderiam avaliar se o fator tempo apresenta influência no comportamento de busca de informação.

No contexto do florescimento atual de programas e incentivos à inclusão digital, acredita-se que estudos exploratórios, que visem identificar e delinear aspectos do comportamento de busca, sejam muito pertinentes à elaboração de programas de desenvolvimento de competências informacionais (information literacy) de usuários brasileiros comuns. Evidentemente, há necessidade de mais estudos rigorosos $\mathrm{e}$ longitudinais para justamente aferir se o comportamento de busca desse tipo de usuário mudaria na medida em que tem mais contato com a web e, portanto, ganharia mais experiência no uso dela.

\section{REFERÊNCIAS}

ALLEN, B.L. Boolean browsing in an information system: an experimental test. Information technology and libraries, Chicago, p.12-20, March 2001.

BRANDT, D. S.; UDEN, L. Insight into mental models of novice internet searchers. Communications of the ACM, New York, n. 7, v. 46, july 2003.

BRUCE, H. Perceptions of the internet: what people think when they search the internet for information. Internet Research: network applications and policy, Hackensack, US, v. 9, n. 3, p. 187-199, 1999.

CHIZZOTTI, A. Pesquisa em ciências humanas e sociais. São Paulo: Cortez, 1991.

CRESPO, I. M.; CAREGNATO, S. E. Comportamento de busca da informação: uma comparação de dois modelos. Em Questão, Porto Alegre, v. 9, n. 2, p. 271-281, jul./dez. 2003.

ELLIS, D. A behavioural approach to information retrieval system design. Journal of Documentation, London, v. 43, n. 3, p. 171-212, Sep. 1989.

FERREIRA, S. M. S. P. Estudos de necessidades de informação: dos paradigmas tradicionais à abordagem Sense-Making. Porto Alegre: ABEBD, 1997. Disponível em: $<$ www.eca.usp.br/nucleos/sense/sumar.htm>. Acesso em: 26/08/2004. Publicado na série Documentos ABEBD, 2. Versão eletrônica com autorização da ABEBD.

FOSTER, A. A nonlinear model of information-seeking behavior. Journal of the American Society for Information Science and Technology, New York, v. 53, n. 3, p. 228-237, 2004.

FOSTER, A.; FORD, N. Serendipity and information seeking: an empirical study. Journal of Documentation, London, v. 59, n. 3, p. 321-340, 2003. Disponível em: $<$ http://www.emeraldinsight.com/0022-0418.htm> . Acesso em: 20 maio 2006.

HEINSTRÖM, J. Fast surfing, broad scanning and deep diving: the influence of personality and study approach on students' information seeking behaviour. Journal of Documentation, London, v. 61, n. 2, p.228-247, 2005. Disponível em: 
<www.emeraldinsight.com/0022-0418.htm>. Acesso em: 20/05/2006.

HIRSH, S. G. Children's relevance criteria and information seeking on electronic resources. Journal of the American Society for Information Science, Washington, v. 50, n. 14, p. 1265-1283, Dec 1999.

HOLSHCER, C.; STRUBE, G. Web search behavior of Internet experts and newbies. Computer Networks, Amsterdam, v. 33, n. 1, p. 337-346, June 2000.

IIZUKA E. S. A exclusão digital e as organizações sem fins lucrativos da cidade de São Paulo: um estudo exploratório. In: ENANPAD. 26: 2002 Salvador. Resumos de trabalhos. Rio de Janeiro: ANPAD 2000. 1 CD-ROM.

JANSEN, B.J.; SPINK, A. An analysis of Web searching by European AlltheWeb.com users. Information Processing and Management, Elmsford, NY, v. 41, p. 361-381, 2005.

JANSEN, B.J.; SPINK, A.; SARACEVIC, T. Real life, real users, and real needs: a study and analysis of user queries on the web. Information Processing and Management, Elmsford, NY, v.36, p.207-227, 2000.

JÄRVELIN, K.; WILSON, T. D. On conceptual models for information seeking and retrieval research. Information Research, Sheffield, v. 9, n. 1, Oct. 2003.

KAR! J. Web information seeking by pages: an observational study of moving and stopping. Information Research, Sheffield, v. 9. n. 4, July, 2004.

KRIKELAS, J. Information seeking behaviour: patterns of academic researchers. Drexel Library Quaterly, Philadelphia, v. 19, p. 5-20, 1983.

KUHLTHAU, C. Inside the search process: information seeking from the user's perspective. Journal of the American Society for Information Science, Washington, v. 42 , n. 5 , p.361-371, 1990.

LIMA, G. A. B. Interfaces entre a ciência da informação e a ciência cognitiva. Ciência da Informação, Brasília, DF, v. 32, n. 1, p. 77-87, jan./abr. 2003.

LUCAS, W.; TOPI, H. Form and function: the impact of query term and operator usage on Web search results. Journal of the American Society for Information Science and Technology, New York, v. 53, n. 2, p. 95-108, 2002.

PIRES, H. E. A importância da biblioteca no combate à exclusão digital na cidade de São Paulo. São Carlos: UFSCar/Departamento de Ciência da Informação, 2003. Trabalho de Conclusão de Curso.

SAVOY, J.; PICARD, J. Retrieval effectivenss on the web. Information Processing and Management, Elmsford, v. 37, p. 543-569, 2001.

SESC. Disponível em: <www.sescsp.com.br> . Acesso em: 14/05/2005.

SILVA, H. et al. Inclusão digital e educação para a competência informacional: uma questão de ética e cidadania. Ciência da Informação, Brasília, DF, v. 34, n. 1, p. 28-36, jan./abr. 2005.

SILVEIRA, H. F. R. da. Internet, governo e cidadania. Ciência da Informação, Brasília, DF, v. 30, n. 2, p. 80-90, maio/ago. 2001.

SLONE, D. J. The influence of mental models and goals on search patterns during web interaction. Journal of the American Society for Information Science and Technology, New York, v. 53, n. 13, p. 1152-1169, 2002.

TAKAHASHI, T. (Org.) Sociedade da Informação no Brasil: Livro Verde. Brasília: Ministério da Ciência e Tecnologia, 2000.

WILSON, T. D. Models in information behavior research. Journal of Documentation, London, v. 55, n. 3, p. 249-270, June 1999. Disponível em: <www:http://aslib.co.uk/aslib>. Acesso em: 3/05/2006. 
WHITE, M.D.; IIVONEN, M. Questions as a factor in Web search strategy. Information Processing and Management, Elmsford, v.37, n.5, p.721-740, 2001.

\begin{abstract}
The information seeking behaviour of the users of Internet access centres that are located in two organizations in a town in the interior of the state of Sâo Paulo was studied. These organizations promote free internet access to the community, thereby contributing to the process of digial inclusion. The analysis of the users' information searching behaviour sought to identify what global search strategy the users used, including search syntax and semantics, information sources and for what the Internet was used. Sixty-one questionnaires with open and closed questions were applied, and the results point to the fact that the users have little familiarity with the Internet, that they carry out one to two searches on average, and that they use few terms in the formulation of the search expression, despite retrieving the information that they require.
\end{abstract}

KEYWORDS: Information seeking behaviour. Digital inclusion. Internet. Information search strategies. Information literacy.

Originais recebidos em: 19/10/2007

Texto aprovado em: 13/03/2008 